\title{
Current Status of Pharmaceutical Care for Elderly Patients In Mainland China
}

\author{
Zhao Yin ${ }^{1}$, Xuedonzg Jia ${ }^{1}$, Fangying $\mathrm{Si}^{1}$, Wan Zhang ${ }^{1}$, Jian Kang ${ }^{1}$, Xiaojian Zhang ${ }^{1}$, Shusen Sun ${ }^{2}$ and \\ Shuzhang Du ${ }^{1 *}$ \\ ${ }^{1}$ Department of pharmacy, The First Affiliated Hospital of Zhengzhou University, China \\ ${ }^{2}$ College of Pharmacy and Health Sciences, Western New England University, USA
}

\begin{abstract}
Purpose: As the aging of Chinese population, health care services for the elderly are becoming increasingly important concerns in China, which has led to the development of pharmaceutical care for elderly patients in mainland China. However, the current status is not thoroughly discussed before. The present study aims to describe the history, current status and the future directions of pharmaceutical care for elderly patients in mainland China.
\end{abstract}

Methods: A comprehensive literature search was undertaken using several databases: Pubmed, Embase, Web of Science, National Knowledge Infrastructure (CNKI) and wanfang following the guidelines for narrative reviews. The search period was from inception of data bases to December 01, 2020. 11 studies are included in this narrative review related to pharmacist-provided geriatric pharmaceutical care.

Findings: The modern national health system of mainland China lay the foundation of pharmaceutical care for elderly patients and promoted its development. Up to now, Chinese clinical pharmacists have provided pharmaceutical care for elderly patients in areas of medication therapy management (MTM), management of medications for infectious diseases and specialty pharmacy services.

Implications: Pharmaceutical care for elderly patients in mainland China has achieved progresses, however, challenges remain. Better education system, training system and career ladder system should be built to improve the competencies of clinical pharmacists and provide better services for elderly patients.

KEYWORDS: Clinical pharmacy; Pharmaceutical care; Elderly patients; Development; Mainland China

\section{INTRODUCTION}

In 2018, there were 167 million adults aged $\geq 65$ years in China, accounting for $11.9 \%$ of the country's total population, and the number will reach 300 million in 2035 [1]. Older people are known to have multiple disease states and take multiple medications. Besides, the pharmacokinetics and pharmacodynamics of elderly patients alter significantly, resulting in higher chances of exposure to drug-related problems, drug-drug interactions or drug-disease interactions [2,3]. There is undesired adverse drug events (ADEs) lead to prolonged hospitalizations, increase morbidity or mortality and increase economic costs $[4,5]$. Therefore, there is a demand to establish pharmaceutical care for elderly patients in mainland China.

The discipline of clinical pharmacy in mainland China was first established in the early 1980s, when the ministry of health $(\mathrm{MOH})$ selected 12 pilot hospitals to tentatively provide clinical pharmaceutical care [6]. Built on the success of these pilot programs, in 2005, the $\mathrm{MOH}$ issued a series of documentations regarding clinical pharmacists and clinical pharmacy [7]. Under the
Quick Response Code:

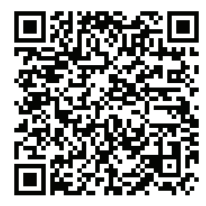

Address for correspondence: Shuzhang Du, Department of pharmacy, The First Affiliated Hospital of Zhengzhou University, China

Received: January 23, $2021 \quad$ Published: February 19, 2021

How to cite this article: Zhao Y, Xuedonzg J, Fangying S, Wan Z, Jian K, Xiaojian Z, Shusen S, Shuzhang D. Current Status of Pharmaceutical Care for Elderly Patients In Mainland China. 20213(1) OAJBS.ID.000255. DOI: $10.38125 / \mathrm{OAJBS} .000255$ 
guidance of these policies, major Chinese pharmacy organizations such as the Chinese Pharmaceutical Association (CPA), the Chinese Medical Association (CMA) and the Chinese Hospital Association (CHA) started to establish national programs and training bases to provide clinical training for pharmacists and preceptors. Along with the healthcare reform in China, hospitals began to hire pharmacists with clinic experiences and skills to provide pharmaceutical direct patients care at hospital wards, including pharmaceutical care to elderly patients. Pharmaceutical care to elderly patients in China has demonstrated its value in improving medication adherence and reduced hospitalization in old patients with chronic diseases, such as chronic obstructive pulmonary disease (COPD) [8].

The concept of pharmaceutical care for elderly patients in China was first described in 2007 [9]. Since then, clinical pharmacists in China have been providing a variety of pharmaceutical care activities for elderly patients both inside and outside hospital. The aim of the present narrative review was to summarize the development and the current status of pharmaceutical care for elderly patients in mainland China. Challenges and future opportunities in geriatric pharmaceutical care will then be discussed.

\section{METHODS}

A comprehensive literature search was undertaken using several databases: Pubmed, Embase, Web of Science, National Knowledge Infrastructure (CNKI) and wanfang following the guidelines for narrative reviews [10]. The search terms, such as "pharmacy services", "pharmaceutical care", "pharmaceutical services", "elderly patients", "elderly", "old”, "old patients", “China”, or "mainland China" and so on, were used appropriately to the database itself. Exclusion critera were non-original articles, nonEnglish or non-Chinese, abstracts without papers, providers were not pharmacists, patients $<65$ years old, and studies from Taiwan, Hongkong and Macao. Some articles in Chinese were excluded without describing specific measurements or interventions. We also searched references lists of included papers manually and duplications were then checked by titles and abstracts. The search period was from inception of data bases to July 31, 2020. The search approach is outlined in Figure 1, and 11 studies are included in this narrative review related to pharmacist-provided geriatric pharmaceutical care.

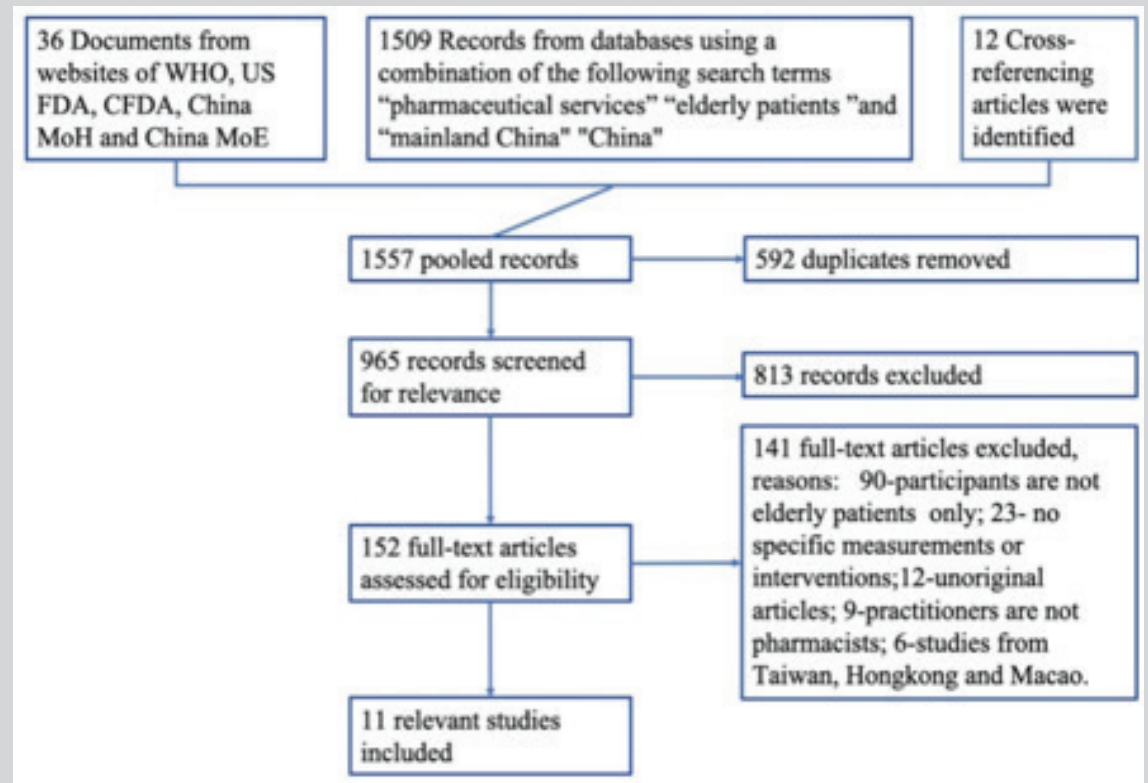

Figure 1: Flowchart of literature search.

Abbreviations: WHO: World Health Organization; CFDA: China Food and Drug Administration; MoH: Ministry of Health; MoE: Ministry of Education.

\section{RESULTS}

From the synthesis of the literature search, pharmacists have explored a variety of pharmaceutical care services to elderly patients in mainland China (Table 1). These activities can be summarized into the following three areas: (1) medication therapy management (MTM); (2) management of medications for infectious diseases; (3) specialty pharmacy services.

\section{Pharmaceutical Care in Chronic Disease Management and the Safe Use of Medications in Elderly Patients}

MTM is a term used to describe a broad range of health care services provided by pharmacists. One of the core elements of MTM is medication therapy review (MTR), which is a systematic process of collecting patient-specific information, assessing medication therapies to identify medication-related problems, developing a prioritized list of medication-related problems, and creating a plan to resolve them [11]. MTM programs are demonstrating positive clinical, economic, and humanistic outcomes across diverse patient population in various patient care settings, including elderly patients both within and outside hospitals [12].

Since 1990, chronic diseases like hypertension and COPD have been the leading causes of death in elderly patients in China [13]. Thus, pharmacists have directed their pharmaceutical care efforts in the MTM of chronic diseases to identify and resolve medicationrelated problems or DRPs. DRPs are events or circumstances involving drug therapy that actually or potentially interferes with desired health outcomes [14]. One described the MTR to community-dwelling older adults $(n=102)$ in the southwest China [15]. Two hospital clinical pharmacists conducted regular MTRs, on average two times a month, at a community health center. Within the study period (May 2015 to July 2016), pharmacist identified 489 DRPs (an average of 4.8 per patient) and almost $98 \%$ of 
patients had at least one DRP. The number of medications for each patient was significantly associated with the presence of DRPs. Pharmacists made 526 recommendations to address the identified DRPs, an average of 1.1 interventions per DRP identified. A total of $68.1 \%$ of these recommendations were accepted by primary care providers and $60.9 \%$ of them were implemented. However, the study did not evaluate the effect of recommendations on clinical outcomes. Poor medication adherence diminishes the health, such as reducing the occurrence rate of DRPs, improving quality of life. Elderly patients with chronic diseases or risk factors frequently require treatment with multiple medications, placing them at increased risk for nonadherence [16]. Pharmacists are providing effective interventions to improve medication compliance and other pharmaceutical care activities to help elderly patients managing their chronic diseases. These interventions include developing individualized drug regimens, attending daily multidisciplinary team rounds, providing education on medications and diseases state management including lifestyle changes to patients, and monitoring medication effectiveness and safety such as adverse drug reactions (ADRs). Several studies described pharmacists' interventions and their positive impacts on the management of hypertension and COPD [17-19].

Table 1: Main studies on the pharmaceutical services in mainland China.

\begin{tabular}{|c|c|c|c|c|c|}
\hline Theme & $\begin{array}{l}\text { Author/ } \\
\text { Year/ } \\
\text { Region }\end{array}$ & Method & Patients/ Setting & $\begin{array}{l}\text { Intervention/ } \\
\text { Measurement }\end{array}$ & Outcomes/ Discoveries \\
\hline Hypertension & $\begin{array}{c}\text { Li } 2018 \\
\text { Taizhou [17] }\end{array}$ & $\begin{array}{c}\text { Randomized } \\
\text { controlled study }\end{array}$ & $\begin{array}{l}102 \text { elderly patients } \\
\text { with hypertension }\end{array}$ & $\begin{array}{c}\text { Pharmacists provided } \\
\text { supervision and consultation } \\
\text { on medications and reviewed } \\
\text { patients' orders. }\end{array}$ & $\begin{array}{c}\text { The control of blood pressure, } \\
\text { compliance, knowledge about } \\
\text { medications and degree of } \\
\text { satisfaction were improved. }\end{array}$ \\
\hline \multirow[b]{2}{*}{ COPD } & $\begin{array}{c}\text { Yan } 2014 \\
\text { Chengdu [18] }\end{array}$ & $\begin{array}{l}\text { Randomized } \\
\text { controlled study }\end{array}$ & $\begin{array}{l}96 \text { elderly patients } \\
\text { with COPD }\end{array}$ & $\begin{array}{l}\text { Pharmacists collaborated } \\
\text { with doctors to develop } \\
\text { treatment plans to monitor } \\
\text { patients' medication processes } \\
\text { and prevent ADRs and drug } \\
\text { interactions. }\end{array}$ & $\begin{array}{l}\text { Pharmacy services improved } \\
\text { CAT scores ( } 20.60 \pm 5.37 \text { VS } \\
23.20 \pm 5.07) \text { and mMRC grade } \\
(2.54 \pm 0.54 \text { VS } 2.83 \pm 0.64) \\
\text { significantly. }\end{array}$ \\
\hline & $\begin{array}{l}\text { Chen } 2016 \\
\text { Haikou [19] }\end{array}$ & $\begin{array}{l}\text { Randomized } \\
\text { controlled study }\end{array}$ & $\begin{array}{l}80 \text { eldely patients with } \\
\text { COPD }\end{array}$ & $\begin{array}{l}\text { Pharmacists provided } \\
\text { pharmacy services like } \\
\text { guidance or supervision on } \\
\text { medication, psychological } \\
\text { guidance and patients } \\
\text { education. }\end{array}$ & $\begin{array}{c}\text { Pharmacy services improved } \\
\text { CAT scores ( } 20.07 \pm 4.96 \text { VS } \\
27.99 \pm 3.75) \text { and mMRC grade } \\
(2.56 \pm 0.49 \text { VS } 2.76 \pm 0.59) \pm \\
\text { hospitalization } \pm 16.53 \pm 6.29 \\
\text { VS } 13.68 \pm 4.27) \mathrm{d} \text { and } \\
\text { treatment costs }(14173.49 \pm 6 \\
293.3 \text { VS } 11274.26 \pm 5930.28 \\
\text { were improved }\end{array}$ \\
\hline \multirow[t]{2}{*}{ DRPs } & $\begin{array}{l}\text { Yang et } \\
\text { al. } 2018 \\
\text { Chongqing } \\
\text { [15] }\end{array}$ & $\begin{array}{l}\text { Retrospective } \\
\text { analysis }\end{array}$ & $\begin{array}{l}102 \text { community- } \\
\text { dwelling older adults }\end{array}$ & $\begin{array}{l}\text { Pharmacists provided } \\
\text { medication therapy review } \\
\text { (MTR), Investigated drug- } \\
\text { related problems for patients }\end{array}$ & $\begin{array}{l}\text { A total of } 489 \text { DRPs were } \\
\text { identified common categories } \\
\text { were under-treated }(27.8 \%) \text {, } \\
\text { over- or under-dose }(18.8 \%) \\
\text { and monitoring (17.8\%); } \\
\text { Pharmacists may play a } \\
\text { vital role in addressing } \\
\text { the DRPs and optimize } \\
\text { pharmacotherapy through } \\
\text { MTR service located in } \\
\text { community health centers }\end{array}$ \\
\hline & $\begin{array}{c}\text { Li } 2017 \\
\text { Chengdu [22] }\end{array}$ & $\begin{array}{l}\text { Cross-sectional } \\
\text { study }\end{array}$ & 6337 older patients & $\begin{array}{l}\text { The Beers and STOPP criteria } \\
\text { were used to identify PIM. A } \\
\text { multivariate logistic regression } \\
\text { study was used to identify the } \\
\text { predictors of PIM use. }\end{array}$ & $\begin{array}{l}\text { A high frequency of PIM in } \\
\text { China was showed. The Beers } \\
\text { criteria had a higher detection } \\
\text { rate and were more sensitive } \\
\text { for assessing PIM of older } \\
\text { adults in China. }\end{array}$ \\
\hline $\begin{array}{l}\text { ADR/ADE } \\
\text { mornitoring }\end{array}$ & $\begin{array}{c}\text { Hu } 2019 \\
\text { Chengdu [25] }\end{array}$ & Delphi study & Inpatients & $\begin{array}{c}\text { Pharmacists conducted a } \\
\text { literature review and a Delphi } \\
\text { process }\end{array}$ & $\begin{array}{l}\text { 42-trigger tool was } \\
\text { developed to identify ADEs in } \\
\text { Chinesegeriatric inpatients. }\end{array}$ \\
\hline $\begin{array}{l}\text { Management } \\
\text { of antiinfection } \\
\text { medications }\end{array}$ & $\begin{array}{l}\text { Zhou } 2019 \\
\text { Beijing [34] }\end{array}$ & $\begin{array}{l}\text { Retrospective } \\
\text { analyse }\end{array}$ & $\begin{array}{l}\text { Elderly patients with } \\
\text { pulmonary infections }\end{array}$ & $\begin{array}{c}\text { Pharmacists analyzed } \\
\text { concentrations of vancomycin } \\
\text { and built and evaluated a } \\
\text { model. }\end{array}$ & $\begin{array}{c}\text { A population } \\
\text { pharmacokinetic model } \\
\text { was established to estimate } \\
\text { the pharmacokinetics } \\
\text { characteristics of Chinese } \\
\text { geriatric patients with } \\
\text { pulmonary infections }\end{array}$ \\
\hline
\end{tabular}




\begin{tabular}{|c|c|c|c|c|c|}
\hline & $\begin{array}{l}\text { Liu et al. } 2019 \\
\text { Beijing [35] }\end{array}$ & $\begin{array}{c}\text { Prospective } \\
\text { population } \\
\text { pharmacokinetic } \\
\text { analysis }\end{array}$ & 41 older patients & $\begin{array}{l}\text { Pharmacists performed } \\
\text { a prospective population } \\
\text { pharmacokinetic analysis }\end{array}$ & $\begin{array}{l}\text { A population pharmacokinetic } \\
\text { model for voriconazole was } \\
\text { developed, Age and CYP2C19 } \\
\text { phenotype were found } \\
\text { to significantly influence } \\
\text { voriconazole clearance, the } \\
\text { optimal dosage strategies } \\
\text { in specific clinical scenarios } \\
\text { were proposed }\end{array}$ \\
\hline & $\begin{array}{l}\text { Zhang } 2017 \\
\text { Shanghai [29] }\end{array}$ & $\begin{array}{l}\text { Cost-effectiveness } \\
\text { analysis }\end{array}$ & $\begin{array}{l}108 \text { elderly patients } \\
\text { with acute lower } \\
\text { respiratory tract } \\
\text { infection }\end{array}$ & $\begin{array}{l}\text { Pharmacists performed a cost- } \\
\text { effectiveness analysis }\end{array}$ & $\begin{array}{l}\text { Levofloxacin ST had relatively } \\
\text { higher cost-effectiveness } \\
\text { ratio for the treatment of } \\
\text { acute lower respiratory tract } \\
\text { infection in elderly patients }\end{array}$ \\
\hline & $\begin{array}{c}\text { Li } 2014 \\
\text { Changsha [8] }\end{array}$ & Experimental study & 84 elderly patients & $\begin{array}{c}\text { Ultrafiltration technology was } \\
\text { employed }\end{array}$ & $\begin{array}{l}\text { The correlation between the } \\
\text { free and total vancomycin } \\
\text { concentration was poor. } \\
\text { Developed a method } \\
\text { that is suitable for use in } \\
\text { protein-binding studies of } \\
\text { vancomycin. }\end{array}$ \\
\hline Cancer & $\begin{array}{l}\text { Jin } 2018 \\
\text { Zhejiang }\end{array}$ & $\begin{array}{l}\text { Randomized } \\
\text { controlled study }\end{array}$ & $\begin{array}{l}90 \text { elderly cancer } \\
\text { patients }\end{array}$ & $\begin{array}{l}\text { Pharmacists provided } \\
\text { medication therapy review } \\
\text { (MTR) and TDM regularly. }\end{array}$ & $\begin{array}{l}\text { The adverse reaction rates of } \\
\text { blood system digestive system } \\
\text { and skin were decreased. } \\
\text { Moreover, the severe adverse } \\
\text { reaction rate decreased } \\
\text { significantly (11.1\% VS } \\
33.3 \%) .\end{array}$ \\
\hline
\end{tabular}

Certain drugs or drug classes are considered to be potentially inappropriate medications (PIMs) in older adults because of their high risk of adverse reactions or lack of sufficient evidence of treatment efficacy, especially there is a safer alternative. The use of PIMs has been linked to adverse health outcomes, such as increased morbidity, hospitalization, and healthcare costs [20]. Explicit criteria such as the American Geriatrics Society (AGS) Beers criteria and the Screening Tool of Older Persons' Prescription (STOPP) in Europe can be used to detect the use of PIMs in older adults [21]. There have been two studies describing the detection of PIMs in Chinese hospitalized older adults using these explicit criteria [5,8]. One study assessed PIMs among 6337 hospitalized patients, and $72.48 \%$ of patients were identified as PIM-users according to the 2012 AGS Beers Criteria [5]. The most prevalent PIMs identified were benzodiazepines (34.40\%). Increasing age, female gender, and the number of prescribed medications predicted PIM use [22]. Another study evaluated PIMs in 863 hospitalized patients using the 2015 AGS Beers Criteria, and $80.2 \%$ of patients received at least on PIM. The most prevalent PIMs identified were protonpump inhibitors, and the number of prescribed medications are an important factor associated with PIM use [23]. However, there are currently no data in China regarding PIMs in community-dwelling older adults.

Elderly patients with multiple co-morbid illness and taking multiple medications are especially vulnerable to ADEs that have high prevalence rates [24]. The global trigger tool is a method of retrospective medical record review that identifies possible harm in hospitalized patients using "triggers". One research aimed to develop an appropriate trigger tool to detect ADEs in Chinese geriatric inpatients by combining a literature review with the Delphi method [25]. In the study, a Delphi process was conducted with a group of experts composed of 13 physicians, 4 clinical pharmacists, and 1 nurse. Based on the survey, 42 triggers in five categories (laboratory index, plasma concentration, antidotes, clinical symptoms and intervention) were retained in the tool. The next step is to test these triggers to identify ADEs in Chinese geriatric inpatients.

However, elderly patients in China are overall suffering from a severe shortage of pharmaceutical services [25], such as the management of warfarin. Warfarin is a widely used oral anticoagulant with a high risk of bleeding. In elderly patients, warfarin therapy is especially challenging because it has a more complex and impressionable metabolic process and more sensitive metabolic characteristics in the body [26]. Many studies talked about assessing the knowledge level regarding warfarin therapy and the corresponding influence [27], providing pharmaceutical care in hospital anticoagulation clinics (HACs) [28] or online through the communicate tool Tencent QQ in general patients [29]. Only one case report shared a successful experience that pharmacists cooperated with physicians to deal with an elderly female with atrial fibrillation [30].

\section{Pharmaceutical Care in the Management of Antimicrobials in Elderly Patients}

Management of antimicrobials in elderly patients is challenging for healthcare providers due to variable pharmacokinetics and pharmacodynamics [31]. Therefore, it is important that pharmacists play a role in the healthcare team to optimize antimicrobial dose, interval and duration in this patient population. In order to evaluate appropriate antimicrobial dosing regimens, one of the frequently used tools by pharmacists is the pharmacokineticpharmacodynamic (PK-PD) model. In 2014, Li et al. [32] employed the ultrafiltration technology to reveal the correlation between the free and total vancomycin concentrations, which was proved to be poor using this method. In 2019, another group estimated the population pharmacokinetics of vancomycin in Chinese geriatric patients with pulmonary infections. In this study, a total of 125 
steady-state trough concentrations from 70 elderly patients were retrospectively collected and a one-compartment model was established. The final validation showed that the model was stable and could be used to develop initial vancomycin dosing regimens for elderly patients [33]. Similarly, a population pharmacokinetic model for voriconazole was developed. It was found out that age and CYP2C19 phenotype significantly influenced voriconazole clearance and the model helped to optimize dosage strategies in specific clinical scenarios [34].

Problems related to the management of perioperative antimicrobial therapy for aged patients have long been a prominent issue globally, pharmacists in China also try to tackle these challenges [35]. One study discussed about the role of pharmacists in intervening the perioperative antimicrobial therapy for elderly patients with diabetes underwent surgery [36]. In the study, pharmacists supervised the utilization of perioperative antimicrobials by taking a role in ward rounding, case discussion and medication consultation. After intervention, the utilization of combination drug therapy, total cost, duration of antibiotics therapy, unreasonable prescription and preventive usage of antimicrobials decreased significantly. However, more need to be done in the management of antimicrobials for elderly patients by pharmacists in China and more important roles should be played in analyzing the antibiotic prescribing patterns, optimizing antibiotic use in inpatients, outpatients and patients dwelling in communities.

\section{Pharmaceutical Care in Oncology in Elderly Patients}

Specialty pharmacy focuses on high cost, high touch medication therapy for patients with complex disease states. And a pharmacist provides specialty pharmacy services to optimize pharmaceutical care outcomes through ensuring appropriate medication use and maximizing adherence [37]. There are about 14 million new cancer patients annually worldwide, and more than 8 million died of this fatal disease [38]. Management of chemotherapeutics and cancer pain control are serious problems for cancer patients. Therefore, the use of specialty pharmacies is expanding in oncology pharmacy practice in the developed countries during the last decades [39]. And studies have shown that clinical pharmacists in China are playing increasingly important roles in the oncology teams to promote therapy effect by providing consultation or treatment recommendations for patients and doctors [40,41]. In 2018, an article talked about pharmacists' role in dealing with common adverse reactions of intravenous chemotherapy in elderly patients with cancer. Ninety elderly patients receiving intravenous chemotherapy were randomly divided into two groups. In the study group, 45 patients underwent clinical treatment via routine pharmaceutical intervention. The occurrence of adverse reactions and the quality of life of patients were observed. Results showed that the incidence of severe adverse reactions in the study group decreased by $11.1 \%(\mathrm{P}<0.05)$ and patients' quality of life increased significantly [41]. On the other hand, the necessity of pain control in elderly cancer patients has been emphasized a long time ago [42]. However, to our knowledge, there are only few case reports discussed the roles of pharmacists in this area. In 2017, a case report showed that a pharmacist participated in the standardized treatment of cancer pain in an elderly patient with advanced gastric cancer. In this study, pharmacist assisted physicians to improve the individualized treatment plan for the patient and guided the rational use of opioids which improved the patient's treatment compliance and treatment effect and ensures reasonable use of medications [43].

\section{DISCUSSION}

The present study describes the current status of pharmaceutical care for elderly patients in mainland China for the first time. In short, pharmaceutical care for elderly patients has achieved desirable progress over the past decades, however, challenges remain.

\section{Lack of Nationwide Standard and Guidance for Pharmaceutical Services}

As mentioned above, pharmacists in China have attempted to provide MTM services or specialty pharmacy services for elderly patients. However, until now, there is few MTM or specialty pharmacy related standard and guidance have been published by pharmacy associations in mainland China. In contrast, as early as 2005, the American Pharmacists Association and National Association of Chain Drug Stores Foundation of America had established a MTM service model, which included 5 core elements: a medication therapy review, a personal medication record, a medication action plan, intervention and/or referral for drug therapy problems, and documentation and follow-up [44]. Developed on the basis of those service models, MTM services are demonstrating positive clinical, economic, and humanistic outcomes across diverse patient population including elderly patients both within and outside hospitals [45]. Therefore, MTM service models are urgently needed in China, so that Chinese pharmacists can learn to provide better MTM services for elderly patients and encourage elderly patients to be full participants in their health care. The ultimate goal is to optimize therapeutic effectiveness, prevent adverse events and achieve optimal medication therapy goals for elderly patients [46].

Similarly, the board of pharmacy specialties (BPS) in the USA has been built to certify pharmacists to improve patient outcomes through specialized care since 1976 [47]. Board certification through the BPS is recognized as a worldwide gold standard for determining which pharmacists are qualified to contribute at advanced practice levels [48]. Now, there are over 42,000 pharmacists are BPS board certified in eleven specialties. Those specialties include ambulatory care pharmacy, cardiology pharmacy, critical care pharmacy, geriatric pharmacy, infectious diseases pharmacy, nuclear pharmacy, nutrition support pharmacy, oncology pharmacy and so on. The BPS certified pharmacists play vital roles in the management of high cost, high touch medication therapy for patients with complex disease states [49].

In short, the establishment of standards, guidelines and laws has been proved to be useful and necessary to promote the development of pharmaceutical services worldwide [50]. China, at its initial stage of the development of pharmaceutical services for elderly patients, should establish its own standards, guidance and laws or learn to make use of those global tools. In 2020, a group of hospital pharmacists from Xiangya Hospital, located in central China, identified PIMs in Chinese community-dwelling older adults using the 2019 American Geriatrics Society (AGS) Beers Criteria [30]. The study concluded that the potential use of PIMs in elderly patients dwelling in communities is high, and the AGS Beers Criteria are a useful tool. However, as mentioned in the study, the medications listed in the AGS Beers Criteria were mainly available in the USA, and some medications that are usually used in other countries such as China may not be included in the list [3]. In 2017, experts from the Rational Drug Use Branch of Chinese Association of Geriatric proposed the PIM criteria for older adults in China on the basis of the 2017 AGS Beers Criteria, which were country- 
specific PIM Criteria [9]. It's a good example that Chinese experts or pharmacy organizations make use of and localize global guidance or criteria.

\section{The Pharmacy Education and Training Systems are Faulty}

A previous review article pointed out that although clinical pharmacy education has become an important part of the Chinese pharmacy education system and has developed a structure including undergraduate, graduate, and postgraduate programs, there are barriers and weaknesses existed [51]. The fact is that the curriculum structure and content for undergraduate programs needed to be improved to make it more practical and systematic, most faculty members of pharmacy colleges lack any clinical experience or background, and the practical elements of clinical pharmacy programs did not fit for purpose in a way. Clinical pharmacists are demonstrating positive outcomes including reducing adverse events [30], improving rational use of medications [52] and decreasing medical cost [53]. Besides, statistically, there are more than 450,000 clinical pharmacists working in clinic wards in mainland China, according to the data from the CMA, which creates opportunities and lays a foundation for the further development of pharmaceutical services for elderly patients in mainland China. The first step we need to take is to improve the nationwide education and training system of clinical pharmacists. To fulfill the urgent demand for skillful and experienced pharmacy graduates, cooperation between pharmacy colleges and hospitals must be strengthened to teach appropriate knowledge and skills to pharmacy students, since teachers with a clinical pharmacy background and clinical experience have been demonstrated to be ideal preceptors for clinical pharmacists [54]. It is therefore suggested that hospital pharmacists play more important roles in teaching college courses. Moreover, more clinical pharmacy training programs should be created by MOE or other related pharmacy associations in China.

\section{Clinical Pharmacists have not been Fully Accepted by Society}

Clinical pharmacists have not been fully accepted by doctors, nurses or patients, and cooperation between clinical pharmacists and other clinical practitioners is limited too [55]. One survey revealed that full-time clinical pharmacy services have made limited progress in China until recently and physicians' perceptions and attitudes toward clinical pharmacy services or clinical pharmacists are not positive enough [56]. This phenomenon results in a negative feedback that pharmacists' wish to face directly to patients is not strong. A survey explored the perceptions of community pharmacists towards the barriers to implementation of pharmaceutical care [57]. It was shown that pharmacists spent most of their work time on performing prescription checks and providing patients with directions for drug administration, dosage or precautions, but they tended to ignore health promotion within and outside of pharmacy settings. The respondents also pointed out that lack of external conditions, time, clinical skills, economic incentive and enough support from other health professionals were the main barriers to the implementation of pharmaceutical care. In nowadays, those factors may still restrict the development of pharmaceutical care services for elderly patients.

\section{Too Consolidated and Dominated by the Change of Health Care System Reform}

In modern China, the health care system underwent two milestone reforms in the 1980s and 2009, respectively. The former one waived the highly centralized and bureaucratic delivery system, and the later one aimed to develop a comprehensive health care system to provide universal coverage of basic health care for all Chinese citizens [58]. Along with the reform of the health care system, the $\mathrm{MOH}$ launched the training and education programs accordingly. The development of clinical pharmacy services has undergone adjustments synchronously with those reforms and policies. As a result, the development of clinical pharmacy didn't focus on the therapy and management of medication while paying too much attention to following and meeting the restrictions of reforms and policies [59]. According to the China Health Statistics Yearbook of 2017, diseases with relative high prevalence rates for older populations in China are cardiovascular diseases, cerebrovascular diseases, digestive system diseases, respiratory diseases, urogenital diseases, and musculoskeletal diseases. Therefore, China should preferentially establish specialty pharmacy service criteria for the diseases listed in the Yearbook, so that pharmacists provide a better cover of the diseases with high morbidity in elderly patients.

\section{CONCLUSION}

Pharmaceutical care for elderly patients in mainland China has achieved progress, however, challenges remain. In order to improve the comprehensive competencies of clinical pharmacists in China, a better education system, training system and career ladder system should be built. Future studies need to pay attention to pharmaceutical services for elderly patients in areas of MTM, management of anti-biotics and specialty pharmacy.

\section{REFERENCES}

1. Global Burden of Disease Cancer Collaboration, Fitzmaurice C, Abate D, et al. (2019) Global, regional, and national cancer incidence, mortality, years of life lost, years lived with disability, and disability-adjusted lifeyears for 29 cancer groups, 1990 to 2017: A systematic analysis for the global burden of disease study. JAMA Oncol 5(12): 1749-1768.

2. Marengoni A, Angleman S, Melis R (2011) Aging with multimorbidity: a systematic review of the literature. Ageing Res Rev 10: 430-439.

3. Obreli Neto PR, Nobili A, De Oliveira BA, Camilo MG, Diogo Pilger, et al. (2012) Adverse drug reactions caused by drug-drug interactions in elderly outpatients: a prospective cohort study. Eur J Clin Pharmacol 68: 1667-1676.

4. Goltz L, Kullak Ublick GA, Kirch W (2012) Potentially inappropriate prescribing for elderly outpatients in Germany: a retrospective claims data analysis. Int J Clin Pharmacol Ther 50:185-194.

5. Cahir C, Bennett K, Teljeur C, Fahey T (2014) Potentially inappropriate prescribing and adverse health outcomes in community dwelling older patients. Br J Clin Pharmacol 77: 201-210.

6. World Health Organization (2015) People's republic of China health system review. Health Systems in Transition.

7. Jing L, Zhiping L (2018) Differences and similarities in clinical pharmacy practice in China and the United States: A Narrative Review. Eur J Hosp Pharm 25(1): 2-5.

8. Wei L, Yang X, Li J, Liu LH, Luo HY, et al. (2014) Effect of pharmaceutical care on medication adherence and hospital admission in patients with chronic obstructive pulmonary disease (COPD): A randomized controlled study. Journal of Thoracic Disease 6(6): 656-662.

9. Shang XJ, Shang XY (2007) The importance and related issues of conducting pharmaceutical services for elderly patients. China Pharmacy 28: 2229-2230.

10. Green BN, Johnson CD, Adams A (2006) Writing narrative literature reviews for peer-reviewed journals: secrets of the trade. Journal of chiropractic medicine 5(3): 101-117. 
11. Anne Burns (2003) Medication therapy management in community pharmacy practice: Core elements of an MTM service (version 1.0). J Am Pharm Assoc 45(5): 573-579.

12. Soliman AM, Carlson A, Dowd B (2013) Impact of medication therapy management (MTM) services on health care costs in polypharmacy patients: evidence from eetrospective claims analysis of commercially insured us population. Value in Health 16: A206.

13. Cui H, Hu YX, Hong CM, Hu GL, Fan L, et al. (2012) A 15 years study of the causes of death among elderly hypertensive patients in a hospital-based sample of China. Arch Gerontol Geriatr 55(3): 709-712.

14. Taegtmeyer AB, Kullak Ublick GA, Widmer N, Falk V, Jetter A, et al. (2012) Clinical usefulness of electronic drug-drug interaction checking in the care of cardiovascular surgery inpatients. Cardiology 123(4): 219-222.

15. Yang J, Meng L, Liu Y, Shusen Sun, Rui Long, et al. (2018) Drug-related problems among community-dwelling older adults in mainland China. Int J Clin Pharm 40(2): 368-375

16. Sinnige J, Braspenning J, Schellevis F (2013) The prevalence of disease clusters in older adults with multiple chronic diseases--A systematic literature review. PLoS One 8(11): e79641.

17. Li J (2018) Effect of pharmacy service intervention on blood pressure control and drug compliance in elderly hypertensive patients in community. J Women's Health Research 24: 118-131.

18. Yan Y (2014) The clinical therapeutic effect of pharmaceutical care on old patients with chronic obstructive pulmonary disease. Chinese Journal of Hospital Pharmacy 6: 489-491.

19. Chen L, Su YY (2016) Impact on the clinical efficacy of elderly patients with chronic obstructive pulmonary disease pharmacy services. International Journal of Respiration 36: 1244-1247.

20. Jaqueline VDeL, Adas SGC, José ÍGA, Hissako SD, Saliba O, et al. (2013) Potentially inappropriate medications used by the elderly: Prevalence and risk factors in Brazilian care homes. BMC Geriatr 13: 52

21. (2012) The American geriatrics society 2012 beers criteria update expert panel. American geriatrics society updated beers criteria for potentially inappropriate medication use in older adults. J Am Geriatr Soc 60(4): 616-631.

22. Li H, Pu S, Liu Q Huang X (2017) Potentially inappropriate medications in Chinese older adults: the beers criteria compared with the screening tool of older persons' prescriptions criteria. Geriatrics Gerontol Int 17(11): 1951-1958.

23. Zhuo Ma, Caixia, Cui XL, Liu LH (2018) Comparison of three criteria for potentially inappropriate medications in Chinese older adults. Clin Interv Aging 14: 65-72.

24. Dolores Toscano Guzmán M, Galván Banqueri M, María José 0 (2017) Development of a trigger tool to identify adverse drug events in elderly patients with multimorbidity. J Patient Saf 6: 14.

25. Hu Q Qin Z, Zhan M, Bin Wu, Ting Xu, et al. (2019) Development of a trigger tool for the detection of adverse drug events in Chinese geriatric inpatients using the Delphi method. Int J Clin Pharm 41: 1174-1183.

26. Dong L, Yan H, Wang D (2008) Antibiotic prescribing patterns in village health clinics across 10 provinces of Western China. I Antimicrob Chemother 62: 410-415.

27. Li X, Sun S, Wang Q Chen B, Qiaoyu Wang, et al. (2018) Assessment of patients' warfarin knowledge and anticoagulation control at a joint physician-and pharmacist-managed clinic in China. Patient Prefer Adherence 12: 783-791.

28. Bounda GA, Ngarambe C, Ge WH (2013) Assessment and evaluation efficacy of a clinical pharmacist-led inpatient warfarin knowledge education program and follow-up at a Chinese tertiary referral teaching hospital. Archives of Pharmacy Practice 4: 168-179.

29. Zhang J, Liu M, Chen Q Wu JM, Cao H, et al. (2017) Outcomes of an online pharmacist-managed anticoagulation clinic for individuals on warfarin therapy living in rural communities. Thrombosis Research 157: 136138.
30. Ernst AA, Weiss SJ, Sullivan A (2012) On-site pharmacists in the ED improve medical errors. Am J Emerg Med 30: 717-725.

31. Giarratano A, Samantha El G, Nicolau DP (2018) Review of antimicrobial use and considerations in the elderly population. Clin Interv Aging 13: 657-667.

32. Bulik CC, Bader JC, Zhang L, Scott A Van Wart, Christopher M Rubino, et al. (2017) PK-PD Compass: bringing infectious diseases pharmacometrics to the patient's bedside. J Pharmacokinet Pharmacodyn 44(2): 161-177.

33. Li X, Wang F, Xu B, Yang Yang, Li Zhang, et al. (2014) Determination of the free and total concentrations of vancomycin by two-dimensional liquid chromatography and its application in elderly patients. J Chromatogr B Analyt Technol Biomed Life Sci 969: 181-189.

34. Zhou Y, Gao F, Chen C, Li Yang, Ting Yang, et al. (2019) Development of a Population Pharmacokinetic Model of Vancomycin and its Application in Chinese Geriatric Patients with Pulmonary Infections. Eur J Drug Metab Pharmacokinet 44(3): 361-370.

35. Liu Y, Qiu T, Liu Y, Jijun Wang, Kai Hu, et al. (2019) Model-based voriconazole dose optimization in Chinese adult patients with hematologic malignancies. Clin Ther 41: 1151-1163.

36. Fennessy BG, Osullivan MJ, Fulton GJ, Kirwan WO, Redmond HP, et al. (2006) Prospective study of use of perioperative antimicrobial therapy in general surgery. Surg Infect 7(4): 355-360.

37. Mingwei L (2016) Pharmaceutical practice for medication management of diabetic patients with type I incision during perioperative period by clinical pharmacists. Evaluation and analysis of drug-use in hospitals of China 16: 1569-1571

38. Schwartz RN, Eng KJ, Frieze DA,Tracy K Gosselin, Niesha Griffith, et al. (2010) NCCN task force report: specialty pharmacy. J Natl Compr Canc Netw 8: S1-S12.

39. Li J, Li Z (2018) Differences and similarities in clinical pharmacy practice in China and the United States: a narrative review. Eur J Hosp Pharm 25(1): 2-5.

40. Wang Y, Huang H, Zeng Y, Junyan Wu, Ruolun Wang, et al. (2013) Pharmacist-led medication education in cancer pain control: A multicentre randomized controlled study in Guangzhou, China. J Int Med Res 41(5): 1462-1472.

41. Wang Y, Wu H, Xu F (2015) Impact of clinical pharmacy services on KAP and QOL in Cancer Patients: A single-center experience. BioMed Res Int 2015: 502431.

42. Jin XH, Meng XB, Zhu YT (2018) Common adverse reactions and pharmaceutical care for intravenous chemotherapy in elderly patients with cancer. Chinese Journal of Clinical Healthcare 21: 328-330.

43. Bernabei Roberto, G Gambassi, K Lapane, F Landi, C Gatsonis, et al. (1998) Management of Pain in Elderly Patients with Cancer. JAMA 279(23): 1877-1882

44. Yang L, Wang LH, Zou ZM (2017) Pharmaceutical practice of standardized treatment on cancer pain in elderly patients by clinical harmacists. Evaluation and analysis of drug-use in hospitals of China 17: 1275-1277.

45. Lemay, Ginger (2012) Medication therapy management in community pharmacy practice. J Med \& Health Rhode Island 95: 281-282.

46. Isetts BJ, Schondelmeyer SW, Artz MB, Lois A Lenarz, Alan H Heaton, et al. (2008) Clinical and economic outcomes of medication therapy management services: the Minnesota experience. J Am Pharm Assoc 48(2): 203-214

47. Bunting BA, Smith BH, Sutherland SE (2008) The Asheville Project: clinical and economic outcomes of a community-based long-term medication therapy management program for hypertension and dyslipidemia. J Am Pharm Assoc 48(1): 23-31.

48. Thompson GA (1976) Board certification for clinical pharmacy. Drug Intell Clin Pharm 10: 168-171.

49. Connor KA, Hamilton LA (2010) Pursuing board of pharmacy specialties certification. AmJ health Syst Pharm 67(14):1146,1150-1151. 
50. Wells BG, Bertin RJ (2001) A vision of pharmacy's future roles, responsibilities and manpower needs in the United States. Board of Pharmaceutical Specialties. Pharmacotherapy 21(1): 126-127.

51. American College of Clinical Pharmacy Board of Regents, Maddux MS. Board of Regents commentary (2013) Qualifications of pharmacists who provide direct patient care: perspectives on the need for residency training and board certification. Pharmacotherapy 33: 888-891.

52. Hu M, Yee G, Zhou NT (2014) Development and current status of clinical pharmacy education in China. Am J Pharm Educ 78: 157.

53. Klopotowska JE, Kuiper R, Van Kan HJ, Anne-Cornelie de Pont, Marcel G Dijkgraaf, et al. (2010) On-ward participation of a hospital. pharmacist in a Dutch intensive care unit reduces prescribing errors and related patient harm: an intervention study. Crit Care 14(5): R174.

54. Moffett BS, Mott AR, Nelson DP, Gurwitch KD (2008) Medication dosing and renal insufficiency in a pediatric cardiac intensive care unit: impact of pharmacist consultation. Pediatr Cardiol 29(4): 744-751.

55. Bird ML, Dunn RL, Hagemann TM, Michael E Burton, Mark L Britton, et al. (2012) Collaboration between a college of pharmacy and a for-profit health system at an academic medical center. Am J Health Syst Pharm 69(13): 1150-1156

56. Liu W, Gerdtz M, Manias E (2016) Creating opportunities for interdisciplinary collaboration and patient-centred care: how nurses, doctors, pharmacists, and patients use communication strategies when managing medications in an acute hospital setting. J Clin Nurs 25(1920): 2943-2957.

57. Li X, Huo H, Kong W, Li Fan, Wang JW, et al. (2014) Physicians perceptions and attitudes toward clinical pharmacy services in urban general hospitals in China. Int J Clin Pharm 36(2): 443-450.

58. Fang Y, Yang S, Feng B, Ni YF, Zhang KH, et al. (2011) Pharmacists perception of pharmaceutical care in community pharmacy: a questionnaire survey in Northwest China. Health Soc Care Community 19(2): 189-197.

59. Li L, Fu H (2017) China's health care system reform: Progress and prospects. Int J Health Plann Manage 32(3): 240-253. 